\title{
Meia-volta na Ciranda: \\ Reflexões sobre decolonialidade na Dança
}

\author{
BALDI, Neilla ${ }^{1}$ \\ MARQUES, Thaís ${ }^{2}$ \\ NASCIMENTO, Djenifer ${ }^{3}$
}

\section{RESUMO}

Este texto fala da decolonialidade na Dança a partir da análise da intervenção artística Meia-volta na Ciranda, criada pelo Grupo de Pesquisa sobre (Es)(Ins)critas do/no Corpo (Corpografias), vinculado ao curso de DançaLicenciatura da Universidade Federal de Santa Maria (UFSM). O objetivo é refletir de que maneira o processo criativo que resultou na obra Meia-volta na Ciranda pode auxiliar as criadoras-intérpretes a repensarem suas práticas artísticas/pedagógicas em Dança em uma perspectiva decolonial. Para isso, apresenta os conceitos de colonialidade e suas diferentes formas, bem como 0 de decolonialidade, e discute as colonialidades presentes nas danças das integrantes do Corpografias. Por fim, o artigo propõe alguns modos de pensar a dança a partir de uma pedagogia decolonial.

Dança. Decolonialidade. Pedagogia da Dança.

Meia-volta na Ciranda:

Reflections about decoloniality in the Dance

\section{ABSTRACT}

This paper discuss about decolonality in the Dance starting from analysis of performance Meia-Volta na Ciranda, created by Research Group about Written Inscription of/in the Body (Corpografias), linked to the Dance Licentiate Course of Universidade Federal de Santa Maria (UFSM). The objective is to reflect how the creative process that resulted in the artistic work Meia-volta na Ciranda can help the creative-interpreter to rethink their artistic-pedagogic practices in Dance in decolonial perspective. For this, it shows the concept of coloniality and their different ways, as the decoloniality, and discuss about the coloniality present in the dances of group members. To finish, the paper proposed some ways of thinking the dance from decolonial pedagogy.

Dance. Decoloniality. Dance pedagogy.

\footnotetext{
${ }^{1}$ Professora Assistente do Curso de Dança-Licenciatura. Doutora em Artes Cênicas pela UFBA. Coordenadora do Grupo de Pesquisa sobre (Es)(Ins)critas do/no Corpo.

${ }^{2}$ Licencianda em Dança pela Universidade Federal de Santa Maria (UFSM). Bolsista do Fundo de Incentivo à Pesquisa (Fipe-JR). Integrante do Corpografias. E-mail:

thaais_cardozo@hotmail.com.

${ }^{3}$ Licencianda em Dança pela Universidade Federal de Santa Maria (UFSM). Integrante do Corpografias.
} 


\section{INTRODUÇÃO}

Os estudos sobre decolonialidade ainda são incipientes na área da Dança (SEVEGNANI, 2018; BALDI, 2017/2018; SILVA; SANTOS, 2017; MACHADO, 2014 e PINTO, 2011). No entanto, as discussões sobre a decolonialidade e a Arte surgem quase junto com as primeiras publicações sobre os estudos pós-coloniais, nos anos 1990. Do mesmo modo que, na última década, tem se intensificado as pesquisas sobre pedagogias decoloniais.

O Grupo de Pesquisa sobre (Es)(Ins)critas do/no Corpo (Corpografias), vinculado ao Curso de Dança-Licenciatura da Universidade Federal de Santa Maria (UFSM) se dedicou, no último ano, a discutir a decolonialidade na dança. A partir dos debates, criou procedimentos de aprenderensinar ${ }^{4}$ dança e a intervenção artística Meia Volta na Ciranda, ambos como parte do projeto de pesquisa Corpografias Dançantes, financiado pelo Fundo de Incentivo à Pesquisa (Fipe-JR) da UFSM. Este texto busca refletir sobre como o processo criativo da performance auxiliou as criadoras-intérpretes a repensarem suas práticas artísticas/pedagógicas, bem como foi importante para discutir sobre os estereótipos presentes na Dança. Para isso, em um primeiro momento apresenta os conceitos acerca do tema e, posteriormente, discute a intervenção, apresentada dia 7 de novembro, no Centro de Educação da UFSM ${ }^{5}$.

\section{Decolonialidade}

As discussões sobre decolonialidade surgiram nos anos 1990, tendo como foco "[...] a emancipação de todos os tipos de dominação e opressão, em um diálogo interdisciplinar entre a economia, a política e a cultura." (ROSEVICS, 2017, p. 189). Os principais teóricos deste campo são: Aníbal Quijano, Catherine Walsh e Walter Mignolo. De acordo com Quijano (2007, p. 93), colonialismo e colonialidade são conceitos distintos. O colonialismo se refere:

[...] a uma estrutura de dominação e exploração, na qual o controle da autoridade política, dos recursos de produção e de

\footnotetext{
${ }^{4}$ Para Paulo Freire (1996, p. 24), "Aprender precedeu o ensinar ou, em outras palavras, ensinar se diluía na experiência realmente fundante de aprender." A partir desse pressuposto e apoiada em Carmen Lúcia Pérez e Carmen Sanches Sampaio (2012), utilizamos aprenderensinar.

${ }^{5}$ Durante o evento VI Ouvindo Coisas, realizado no Centro de Educação da UFSM, nos dias 7 e 8 de novembro de 2018.
} 
trabalho de uma população determinada tem identidade diferente e cujas sedes centrais estão longe, em outra jurisdição territorial.

Segundo ele, o colonialismo nasce na América e, portanto, é anterior à colonialidade. Esta foi forjada no colonialismo, sem o qual não poderia ter imposto à intersubjetividade do mundo de forma tão enraizada. Assim, a colonialidade se relaciona "[...] à forma como o trabalho, o conhecimento, a autoridade $e$ as relações intersubjetivas se articulam entre si através do mercado capitalista mundial e da idéia de raça." (TORRES, 2007, p. 131 apud OLIVEIRA; CANDAU, 2010, p. 18). Isto significa que a colonialidade se mantém viva em livros didáticos, na cultura e em vários aspectos da vida cotidiana e se apresenta, segundo os principais teóricos do campo, em colonialidade do poder, do saber, do ser e do conviver.

Walsh (2008, p. 136) chama de colonialidade de poder o "[...] estabelecimento de um sistema de classificação social baseada em uma hierarquia racial e sexual e na formação e distribuição de identidades sociais de superior e inferior [...]". Por sua vez, segundo ela, a colonialidade de saber se manifesta "[...] pelo posicionamento do eurocentrismo como a perspectiva única de conhecimento, que descarta a existência e viabilidade de outras racionalidades epistêmicas e outros conhecimentos [...]". (WALSH, 2008, p. 137) Já a colonialidade do ser é "[...] a negação de um estatuto humano para africanos e indígenas, por exemplo, na história da modernidade colonial." (OLIVEIRA; CANDAU, 2010, p. 22) Enquanto a colonialidade do conviver está relacionada aos binarismos, à negação da relação milenar espiritual e integral, ao ressaltar o poder do indivíduo sobre o restante.

Além da constituição das quatro colonialidades, podemos enxergar atualmente também o surgimento de pedagogias decoloniais. A partir das leituras realizadas no grupo de pesquisa, sobretudo de Silva e Santiago (2016), Oliveira e Candau (2010), Penna (2014), Silva e Santos (2017) e Rosevics (2017) identificamos as seguintes palavras-chave como fundantes nas pedagogias decoloniais: singularidade, experiência, conhecimento corporalizado, conhecimento localizado geopoliticamente, problematizar, aprender a desaprender e desconstrução.

Nas pedagogias decoloniais, os(as) estudantes são respeitados em suas singularidades, o que significa também que suas experiências anteriores, conhecimentos prévios e suas vidas têm de ser consideradas no ato educativo. Esta singularidade permite a coletividade, uma vez que, de acordo com Palermo (2014, p. 137):

Pensar a partir do local, a partir do pertencimento, é construir um lugar epistêmico que inclua as diferenças, que reconhece os silenciados, os discursos que falam em seu nome e que fazem do silêncio uma metáfora poética. 
No entendimento decolonial, o conhecimento é corporalizado, isso significa, por exemplo, valorizar não apenas o que seria intelectual, mas também as emoções e o movimento. Do mesmo modo, acreditamos que esta corporificação pode ser entendida como a construção de corpografias, ou seja, de (es)(ins)critas do/no corpo, um corpo-sujeito que tem suas memórias, suas marcas, que é inscrito por elas e, ao mesmo tempo escreve (BALDI, 2014). Este conhecimento, porque corporalizado, também 0 é localizado geopoliticamente: onde nasço ou onde vivo se reverberam no meu modo de operar, pensar, questionar, viver etc. Por fim, as pedagogias decoloniais problematizam o conhecimento e nos ensinam a aprender a desaprender e a desconstruir. A partir disso, a prática pedagógica é um processo contínuo. Em Dança, isso significa valorizar 0 modo como se chega a determinados conceitos e conteúdos e não o produto final.

Além disso, Mignolo e Vásquez (2017, p. 496) afirmam que a pedagogia decolonial "[...] enfatiza a emoção sobre a razão, a história pessoal sobre os princípios e métodos disciplinares." Acreditamos, então, que pensar a decolonialidade em Arte e, aqui, mais especificamente em Dança, vai ao encontro do que preconiza a pedagogia decolonial.

\section{Meia-volta na Ciranda}

A criação que resultou na intervenção Meia-volta na Ciranda surgiu de uma vontade de materializar em dança as discussões do grupo sobre decolonialidade. Como cada integrante possuía experiências extra-acadêmicas de uma forma de Dança, utilizamos como princípios as colonialidades das danças de cada uma, que eram: balé clássico, danças tradicionais gaúchas e danças urbanas.

Nas Danças Tradicionais Gaúchas, identificamos a presença do machismo, que pode ser caracterizado como uma colonialidade de poder. Nesta dança, a prenda (mulher que dança) é quem faz movimentos leves e delicados, enquanto os peões (homens) ficam os movimentos que demonstram força e virilidade, eles tentam conquistar a prenda. A partir da identificação destes papeis no contexto das Danças Tradicionais Gaúchas fizemos alguns questionamentos. Será que não existiria também na sociedade mulheres fortes e viris? Seria essa dança um reflexo de ideais machistas da época em que surgiu? Outra questão identificada nas Danças Tradicionais Gaúchas também foi a presença de um embranquecimento e invisibilização das culturas negras e indígenas, pois quando estas danças foram sistematizadas, o legado destas culturas foi apagado - ou seja, há uma colonialidade de saber e de ser.

Nas Danças Urbanas, houve um processo de elitização das mesmas e consequente afastamento dos seus públicos originais. As mesmas nasceram 
nas periferias das cidades, no século passado, mas hoje são ensinadas em escolas de dança privada, sem acesso às classes mais pobres. Suas origens marginais muitas vezes são negligenciadas. Ou seja, há aqui uma colonialidade do poder e do ser. Além disso, algumas destas danças são discriminadas, sobretudo na educação básica, exatamente por suas origens, como é o caso do funk.

Por sua vez, no balé clássico identificamos várias colonialidades. Tratase de uma dança que valoriza o virtuosismo, no qual o corpo é um instrumento, que sempre pode mais, ou seja, que precisa ser 'vencido', o que se traduz em reproduzir o movimento até a sua 'perfeição' ou levantar a perna mais alto, por exemplo. Este pensamento está alinhado ao que se convencionou chamar de colonialidade do conviver. Além disso, é uma dança que busca um corpo com padrão europeu, o que significa a presença da colonialidade do saber. Do mesmo modo como em outras danças, no balé clássico há os movimentos específicos para homens e outros para mulheres, sendo a leveza a característica marcante para o gênero feminino e a virilidade, para o masculino (colonialidade de poder).

Identificamos também que no modo como têm sido ensinadas, todas as danças aqui discutidas apresentam a colonialidade do saber, a partir na ênfase no repertório, ou seja, no ensino dos 'passos' codificados, como se apenas estes fossem os conteúdos de dança. No entanto, a dança possui outros conteúdos, como a criação, a musicalidade, aspectos anatômicos etc. Muitas vezes, ao dar ênfase no repertório, professores e professoras esquecem-se dos demais conteúdos e o que vemos são estudantes reproduzindo movimentos, mas sem saber, por exemplo, criar, ou desconhecendo o contexto da codificação destes movimentos.

A partir da identificação das colonialidades de cada forma de dançar, procuramos maneiras de transformar em movimento as referidas questões. Trabalhamos inicialmente com criações individuais. Ou seja, cada integrante do Corpografias criou uma sequência sobre as suas colonialidades. Depois, compartilhamos as pequenas células coreográficas no grupo e cada uma ${ }^{6}$ foi dando sua opinião acerca das movimentações de modo a construirmos a dramaturgia da intervenção. Tentamos mostrar em gestos e movimentos os estereótipos destas danças, suas colonialidades, assim como propostas de confrontação a elas. Neste sentido, por exemplo, movimentos considerados típicos de homens, nas Danças Tradicionais Gaúchas, eram reproduzidos por mulheres. Assim como, no caso do balé, 'brincamos' com a perfeição, realizando alguns movimentos de forma repetida, até que ficassem quase que rascunhos...

\footnotetext{
${ }^{6} \mathrm{Na}$ ocasião o grupo estava formado por quatro alunas do Curso de Dança-Licenciatura e sua coordenadora, ou seja, apenas mulheres.
} 
O nome da performance (Meia-volta na Ciranda) surgiu em contraponto à música de Edu Lobo e Chico Buarque, Ciranda da Bailarina, que apresenta a bailarina de maneira estereotipada, como uma pessoa perfeita. Durante a composição da cena, escolhemos alguns trechos da letra da música, que eram repetidos, em voz alta, pelas bailarinas, na cena. Buscamos trechos que, para nós, estavam relacionados às colonialidades aqui discutidas. Ao fundo, a música que tocou era em versão instrumental.

\title{
Decolonialidades na Dança
}

Além do exposto, conforme Baldi (2017/2018, p. 297), é possível perceber ainda que a colonialidade em dança se dá em várias frentes:

\begin{abstract}
Há um tipo de dança pensado como universal - o balé clássico, considerado ainda por muitas pessoas como técnica de base bem como um modo de transmissão deste saber, centrando-se nxs professorxs como detentorxs do conhecimento, cujo modelo de movimento deve ser repetido e aprimorado, bem como uma tendência à valorização da individualidade. Além disso, os saberes privilegiados nas aulas de dança são aqueles considerados como técnicos: eixos, giros, saltos, posturas etc. Quais são os saberes dxs alunxs? O que elxs têm a contribuir para as aulas de dança? Como os saberes de $x$ se relacionam com os saberes dxs demais?
\end{abstract}

Como dito anteriormente, a problematização é uma das características das pedagogias decoloniais e, portanto, ao discutirmos a colonialidade na dança, acabamos por problematizar os modos de dançar, produzir e aprenderensinar dança.

Criar a partir da discussão das colonialidades da dança nos ajudou a compreendê-las melhor. A performance permitiu que 'materializássemos' em dança as discussões. Ou seja, em um movimento decolonial, corporificamos o conhecimento. Do mesmo modo que a criação da performance foi um momento de 'transpormos' para a dança o que vínhamos discutido, ao longo do ano, no Corpografias. Isto porque, como explicado anteriormente, ainda são incipientes as pesquisas sobre Dança e decolonialidade e, portanto, neste período, nos debruçamos sobre leituras gerais que enfocassem as pedagogias decoloniais ou que discutissem Arte e decolonialidade. Ao transpormos, temos aqui outro tipo de entendimento de um conhecimento localizado geopoliticamente: na dança, no Brasil, no Rio Grande do Sul, em um curso de formação de professores(as) de dança. Com Meia-volta na Ciranda vimos um modo de utilizarmos nossas discussões em uma produção artística, mas percebemos também a potencialidade criativa deste debate.

Do mesmo modo, ao apresentarmos a performance, percebemos o quanto existe um imaginário do que seja Arte e do que seja Dança, de que 
'movimentos borrados' (ou quase rascunho, como escrito anteriormente) são elencados como 'simples' e que às vezes a ironia do estereótipo não é percebida. Tentamos mostrar os estereótipos e suas fricções exatamente para suscitar discussões a respeito do fazer dança: que dança aprendemosensinamos, como aprendemosensinamos, que dança consumimos?

Identificar as colonialidades - e mostrá-las na performance - significa também apontar possíveis caminhos de combatê-las. Assim, do ponto de vista da colonialidade do poder, podemos propor que todos(as) estudantes aprendam todos os movimentos codificados de uma determinada dança e não apenas aqueles específicos para um gênero - como vimos no balé clássico e nas Danças Tradicionais Gaúchas. Do mesmo modo que podemos combater o machismo presente nas relações, em sala de aula.

Quando consideramos a colonialidade do saber, verificamos que a maior parte das danças dá ênfase a um tipo de conhecimento: o dos movimentos codificados. Mas sabemos que existem outros conteúdos e, neste caso, nossas aulas devem também abrangê-los. Neste sentido, o aprender a desaprender e a desconstrução, das pedagogias decoloniais, podem se manifestar no aprender a 'usar' o que aprendeu: como transformo os 'passos' em uma sequência coreográfica, por exemplo. Em uma analogia à língua portuguesa: como construo frases a partir das palavras aprendidas. Ou ainda podemos propor desconstruções a partir da pesquisa de movimento, uma vez que comumente a dança é ensinada a partir da reprodução de movimentos: o(a) professor(a) faz, o(a) estudante copia.

Resgatar os legados dos povos indígenas e africanos em nossas danças (ou em danças trazidas para o Brasil) também é uma forma de decolonizar do ponto da colonialidade do ser. Problematizar os cânones da dança, o que se considera Dança - por exemplo o preconceito em relação ao funk, um tipo de música que tem também uma dança, no escopo das danças urbanas - é uma decolonialidade do ser e do saber em Dança. Para Penna (2014, p. 197), um aspecto da dimensão pedagógica decolonial é:

[...] a compreensão da nossa realidade (latino-americana) como marcada por um processo histórico e sociológico de opressão e colonização. O que em si pressupõe um ponto de partida, ou um lugar de fala, distinto do lugar a partir do qual o conhecimento hegemônico é enunciado. E isto marca nossa produção, nossos quadros interpretativos, nossas formas de compreender e classificar o mundo.

Compreender isso, em Dança, é situarmo-nos (conhecimento geopoliticamente localizado). Somos um país de origem indígena - e que, portanto, dançava - que foi colonizado por portugueses, que trouxeram negros escravizados; e que viveu, ao longo de séculos, diversas imigrações. Portanto, 
como brasileiros(as), somos miscigenados(as). Devemos reconhecer a hibridização de culturas aqui presentes e suas formas de produzir Danças, bem como compreender que alguns modos de dançar da atualidade são resistências. Pois, como nos lembra Filho (2014, p. 278):

Toda obra de arte, aceita ou não como obra de arte, oferece conhecimentos significativos a respeito da diversidade e das potencialidades dos grupos que a produziu. Temos, então, nas produções funk, um meio formidável para a compreensão de jovens que, seguramente, representam parte expressiva da juventude brasileira.

Compreender e valorizar a singularidade dos(as) nossos(as) estudantes, considerar suas vivências e conhecimentos prévios e realizar aulas que não imponham o virtuosismo, que pratiquem uma reprodução de movimento consciente e não mecânica são caminhos para a decolonialidade do conviver. Democratizar o ensino da dança, de modo a valorizar todos os biotipos e não acreditar que existem as pessoas 'mais talhadas' para práticas dançantes também é uma forma decolonial de aprendizadoensino desta Arte.

Além disso, nossas discussões acerca da decolonialidade, para a produção da performance, mas também ao longo do ano, nos levaram a produzir atividades decoloniais de dança, assim como a refletir sobre as relações em sala de aula. Por exemplo, nas classes de dança é comum que os(as) estudantes que sabem mais (ou acham que sabem) se colocarem à frente, assim como o(a) professor estar na frente de todos(as). A partir de uma perspectiva decolonial, acreditamos que as relações não devam ser verticalizadas, mas multidirecionais. Desse modo, podemos trabalhar em formações em roda, em grupos ou, quando precisarmos fazer fileiras, propor rodízio, de modo que todos(as) passem pela frente ou pelo momento de liderança.

\section{Considerações Finais}

A criação artística Meia-volta na Ciranda permitiu que identificássemos as colonialidades na Dança, compreendêssemos melhor os conceitos acerca da decolonialidade, bem como propuséssemos outros modos de pensar a Dança. Assim, ao propor uma dança - em processos artísticos/pedagógicos em uma perspectiva decolonial, talvez estejamos não apenas vivendo uma aprendizagem outra mas, também, uma dança outra.

A partir da realização do referido processo criativo foi possível compreender o quão importante foi materializar em forma de Dança as discussões acerca da decolonialidade e repensar nossas práticas artísticas e pedagógicas em Dança. Como poderíamos usar essas discussões em nossas 
práticas docentes? Como isso poderia se materializar em nossa produção artística? Como os nossos processos artísticos podem refletir uma pedagogia decolonial? Estas questões ficaram latentes ao longo do processo de criação, bem como da escrita deste texto. Apontamos alguns caminhos, mas sabemos que muitos outros podem surgir.

Acreditamos que a coerência entre a prática e a teoria, como já dizia Freire (1996), se dê na autorreflexão do(a) professor(a) de Dança que se reconhece inacabado. Refletir sobre um processo de criação em Dança nos ajuda a repensar nossos fazeres cotidianos nesta arte. Além disso, a identificação (e compreensão) das colonialidades presentes na dança nos permite revê-las. Ora, Freire (2005 apud PENNA, 2014) dizia que:

[...] uma das formas pelas quais o educador poderia ajudar no sentido de superação da mitologia opressiva - e, por conseguinte, na superação da "colonização do ser" - é por meio da explicitação de alguns dos mitos sobre os quais a dominação se fundamenta: "o que há de fazer é propor aos oprimidos os slogans dos opressores, como problema, proporcionando-se, assim, a sua expulsão de dentro dos oprimidos" (Freire, 2005, p. 99). A problematização das categorias e esquemas de interpretação subjacentes ao eurocentrismo, notadamente através da explicitação dos mitos que o constroem, é justamente a proposta do pos-colonialismo latino-americano. (PENNA, 2014, p. 191)

O que queremos afirmar é que artístico-pedagogicamente podemos expor e discutir estas colonialidades como forma de problematizá-las e superálas. Para nós, a performance nos permitiu identificá-las, compreendê-las e refutá-las. Acreditamos que o mesmo pode ser vivido por nossos(as) estudantes ou por plateias de nossa performance.

Acreditamos ainda que, se o pensamento decolonial deseja fundar um pensamento 'outro' (WALSH, 2008), então deseja mudanças, também na educação, e a educação em Arte e em Dança podem ajudar a propor novas formas de aprendizagemensino em outras áreas. Aqui, identificamos questões que podem ser discutidas também em outras áreas do conhecimento: quais as colonialidades do aprenderensinar Geografia ou da Matemática, por exemplo? Quais as colonialidades presentes na escola, de modo geral? São semelhantes às encontradas na Dança? As decolonialidades propostas para a Dança podem ser replicadas em outras áreas do conhecimento?

Concordamos com Walsh (2013, p. 67), quando afirma que "[...] a decolonialidade não é uma teoria a seguir, mas um projeto a assumir. É um projeto de ação para pedagogicamente andar." Viver a dança decolonialmente é aprenderensiná-la de uma forma outra, é produzi-la de maneira outra, bem como fruí-la de um jeito outro. Assim, nossa dança decolonialmente é uma dança em movimento, sempre. Movimento de aprender a desaprender, de 
Meia-volta na Ciranda:

Reflexões sobre decolonialidade na Dança

problematizar etc. É estar em processo, andando como afirma Walsh (2013), é uma dança decolonialmente dançando...

\section{Referências}

BALDI, Neila. Para pensar o aprenderensinar dança a partir de uma perspectiva decolonial. Revista Interinstitucional Artes de Educar. Rio de Janeiro, V. 3, N. 3, p. 293-315 (out/2017 - jan/2018).

BALDI, Nélia. (Ins)(Es)critas no/do corpo dançante. In: CONGRESSO CONFAEB. Anais..., XXIV, Londrina, 2014.

FREIRE, Paulo. Pedagogia do Oprimido. São Paulo: Paz e Terra, 1996.

FILHO, Aldo Victorio. Culturas juvenis para além dos interditos culturais: o funk carioca, potência e beleza. In: TOURINHO, Irene. MARTINS, Raimundo. Pedagogias culturais. Santa Maria: Editora UFSM, 2014. p.275-292.

MACHADO, Felipe. Entre rodas de dança e coreografias: notas para um pensamento dançarino. Horizonte de la Ciencia, Huancayo-Peru, v.4, n.7, diciembre 2014, p. 1523.

MIGNOLO, Walter. VÁSQUEZ, Rolando. Pedagogía y (de)colonialidad. In: WALSH, Catherine. Pedagogías decoloniales: práticas insurgentes de resistir, (re)existir y (re)vivier. Tomo II. Quito: Ediciones Abya-Yala, 2017. p.489-508.

OLIVEIRA, Luiz Fernandes de. CANDAU, Vera Maria Ferrão. Pedagogia decolonial e educação antirracista e intercultural no Brasil. Educação em Revista, Belo Horizonte, v.26, n.01, p.15-40, abr. 2010.

PALERMO, Zulma. Irrupcion de saberes "otros" en el espacio pedagógico: hacia una "democracia decolonial" In: BORSANI, María Eugenia. QUINTERO, Pablo (comp.). Los desafíos decoloniales de nuestros días: pensar en colectivo. Neuquén: Educo Editorial de la Universidad Nacional del Comahue, 2014. p.123-150.

PENNA, Camila. Paulo Freire no pensamento decolonial: um olhar pedagógico sobre a teoria póscolonial latinoamericana. Revista de estudos e Pesquisas sobre as Américas. V.8, N.2, p.181-199, 2014.

PINTO, Maria Thereza Fabião da Silva. Danças africanas e interculturalidade: mundividência e e experiência de corpo em Portugal. 2011. Dissertação (Mestrado em Dança) - . Escola de Dança, Universidade Federal da Bahia, Salvador, 2017.

QUIJANO, Aníbal. Colonialidad del poder y clasifi cación social. In: CASTRO-GÓMEZ, Santiago. GROSFOGUEL, Ramón. (Ed.) El giro decolonial: Refl exiones para una diversidad epistémica más allá del capitalismo global. Bogotá: Siglo del Hombre Editores; Universidad Central, Instituto de Estudios Sociales Contemporáneos y Pontifi cia Universidad Javeriana, Instituto Pensar, 2007, p. 93-126.

ROSEVICS, Larissa. Do pós-colonial à decolonialidade. In: CARVALHO, Glauber. ROSEVICS, Larissa (Org). Diálogos Internacionais: reflexões críticas do mundo contemporâneo. Rio de Janeiro: Perse, 2017. 
SEVEGNANI, Claudinei. Desfetichizar a latinidade, desencantar o passado, decolonizar a dança. IN: SEMINÁRIO CULTURA E DUCAÇÃO. Anais... 3, UEMS, Campo Grande, 2018.

SILVA, Claudilene. SANTIAGO, Eliete. Pensamento negro e educação intercultural no Brasil. Interterritórios - Revista de Educação, Recife, v.2, n.3, p. 78-100, p. 2016.

SILVA, Luciane. SANTOS, Iraicyra Falcão dos. Colonialidade na dança e as formas africanizadas de escrita de si: perspectivas sul- sul através da técnica Germaine Acogny. Conceição-Concepction, Campinas, v. 6, n. 2, p. 162-173, jul./dez. 2017.

WALSH, Catherine. Interculturalidad, plurinacionalidad y decolonialidad: las insurgencias político-epistémicas de refundar el Estado. Tabula Rasa. Bogotá Colombia, No.9: 131-152, julio-diciembre 2008. 